LM-01K046

May 4, 2001

\title{
Corrosion Behavior of 304 Stainless Steel in High Temperature, Hydrogenated Water
}

\author{
S.E. Ziemniak, M. Hanson
}

\begin{abstract}
This report was prepared as an account of work sponsored by the United States Government. Neither the United States, nor the United States Department of Energy, nor any of their employees, nor any of their contractors, subcontractors, or their employees, makes any warranty, express or implied, or assumes any legal liability or responsibility for the accuracy, completeness or usefulness of any information, apparatus, product or process disclosed, or represents that its use would not infringe privately owned rights.
\end{abstract}


Corrosion Behavior of 304 Stainless Steel in High Temperature, Hydrogenated Water

S. E. Ziemniak

M. Hanson

\section{Lockheed Martin Corporation}

KAPL, Inc.

P.O. Box 1072

Schenectady, New York 12301-1072 


\begin{abstract}
The corrosion behavior of an austenitic stainless steel (UNS \$30400) has been characterized in a 10,000 hour test conducted in hydrogenated, ammoniated water at $260^{\circ} \mathrm{C}$. The corrosion kinetics were observed to follow a parabolic rate dependency, the parabolic rate constant being determined by chemical descaling to be $1.16 \mathrm{mg} \mathrm{dm}^{-2} \mathrm{hr}^{-1 / 2}$. X-ray photoelectron spectroscopy, in combination with argon ion milling and target factor analysis, was applied to provide an independent estimate of the rate constant that agreed with the gravimetric result. Based on the distribution of the three oxidized alloying constituents $(\mathrm{Fe}, \mathrm{Cr}, \mathrm{Ni})$ with respect to depth and elemental state, it was found that: (a) corrosion occurs in a non-selective manner, and (b) the corrosion film consists of two spinel oxide layers - a ferrite-based outer layer $\left(\mathrm{Ni}_{0.2} \mathrm{Fe}_{0.8}\right)\left(\mathrm{Fe}_{0.95} \mathrm{Cr}_{0.05}\right)_{2} \mathrm{O}_{4}$ on top of a chromite-based inner layer $\left(\mathrm{Ni}_{0.2} \mathrm{Fe}_{0.8}\right)\left(\mathrm{Cr}_{0.7} \mathrm{Fe}_{0.3)_{2}} \mathrm{O}_{4}\right.$. These compositions agree closely with the solvi phases created by immiscibility in the $\mathrm{Fe}_{3} \mathrm{O}_{4}-\mathrm{FeCr}_{2} \mathrm{O}_{4}$ binary, implying that immiscibility plays an important role in the phase separation process.
\end{abstract}

KEYWORDS: austenitic stainless steel, aqueous corrosion, hydrothermal reactions, X-ray photoelectron spectroscopy, high temperature water, Auger electron spectroscopy, type 304 stainless steel, corrosion oxide analysis, Argon ion sputter rate, spinel oxides, target factor analysis. 


\section{INTRODUCTION}

The discovery [1] and development [2] of austenitic stainless steels dates back to the first decades of the Twentieth Century. These alloys have since become well-known for their passivity and excellent resistance to corrosion in high temperature water. Thus, they were the material of choice for the first water-cooled nuclear reactors.

A remarkable characteristic of the corrosion oxides that form on these alloys during exposure to high temperature water is their duplex spinel nature $[3,4]$. Spinels are oxides of the type $\mathrm{AB}_{2} \mathrm{O}_{4}$, where $\mathrm{A}=$ $\mathrm{Fe}(\mathrm{II})$ and $\mathrm{Ni}(\mathrm{II})$ and $\mathrm{B}=\mathrm{Fe}(\mathrm{III})$ and $\mathrm{Cr}(\mathrm{III})$. The inner spinel is $\mathrm{Cr}(\mathrm{III})$ rich, while the outer is $\mathrm{Fe}(\mathrm{III})$ rich. This behavior is consistent with expectation, since chromium is recognized as the protective alloying constituent, and its minimum alloying content is well established. Recently a detailed physicochemical model was developed to explain the general corrosion behavior of austenitic stainless steel in high temperature water [5]. The model is based on two hypotheses: (1) alloy oxidation occurs non-selectively and (2) composition of the two oxide layers is controlled by differences in the diffusion rates of the alloying constituents.

Based on review of available literature, quantitative experimental evidence is lacking regarding the non-selective oxidation hypothesis (which assumes each alloying constituent passes congruently into the oxide phase), nor has the stoichiometric composition of each oxide layer been quantified. The present work was undertaken to quantify both.

\section{EXPERIMENTAL}

Corrosion specimens of austenitic type 304 stainless steel (UNS S30400) were exposed at $260^{\circ} \mathrm{C}$ in a flowing autociave facility $\left(10 \mathrm{~cm}^{3} \mathrm{~min}^{-1}\right)$ comprised of a one-liter, type 347 stainless steel (UNS 
S34700) vessel, and fed from stainless steel tanks containing deionized, hydrogen-sparged, ammoniated water. The dissolved hydrogen concentration was $45 \mathrm{scm}^{3} / \mathrm{kg}$ water and ammonia additions provided $\mathrm{pH}\left(@ 260^{\circ} \mathrm{C}\right)=6.45$. Test shutdowns, along with specimen removals and insertions, occurred intermittently, so that exposure times ranged between 1000 and 10,000 hours.

In anticipation of the precision corrosion film analyses to be performed, one side of each corrosion specimen $\left(5 / 8^{\prime \prime} \times 3 / 4^{\prime \prime} \times 1 / 16^{\prime \prime}\right)$ was highly polished ( $<6 \mu$ in AA) using diamond grit paste. Larger, machined coupons $\left(4^{\prime \prime} \times 3 / 4^{\prime \prime} \times .032^{\prime \prime}\right)$ were also prepared and exposed along with the polished specimens. The larger surface area of the former permitted the total quantity of oxidized base metal to be accurately determined via application of standard chemical descale (i.e., gravimetric) methodology.

\section{ANALYTICAL PROCEDURES}

After completion of the test exposure period, the corrosion specimens were subjected to three types of analyses to characterize the states of their oxidized surfaces: (a) scanning electron microscopy (SEM), (b) grazing incidence X-ray diffraction (XRD) and (c) X-ray photoelectron spectroscopy (XPS). Each of these procedures is described below:

\section{Scanning Electron Microscopy (SEM)}

This procedure was employed to characterize gross features of the oxidized surface, including morphology of the outer layer of corrosion oxides, via high magnification photographs (2000 $10,000 \mathrm{X})$. The energy dispersive analysis of X-rays (EDX) attachment to the SEM probe was used to provide semi-quantitative estimates of surface oxide crystal compositions using calibrated standards for $\mathrm{O}$ (quartz), $\mathrm{Fe}, \mathrm{Cr}, \mathrm{Ni}$, and $\mathrm{Mn}$. 


\section{Grazing Incidence X-Ray Diffraction (GIXRD)}

This technique was used to identify the oxide phase(s) present (unit cell dimensions) and to estimate the thickness of the corrosion layer. The measurements were carried out using copper radiation $(\lambda=$ $1.542 \AA$ ) and a D8 diffractometer equipped with a Soller slit and a LiF flat crystal monochrometer on the diffracted beam side.

GIXRD measurements were initially performed for a series of $\phi<1^{\circ}$ with a $0.05 \mathrm{~mm}$ incident beam slit for $2 \theta$ between 15 and $98^{\circ}$. Due to the relatively large corrosion oxide thicknesses encountered, no base metal reflections were observed in any of the spectra. Therefore, these spectra were used only to identify the metal oxide phase present in the corrosion layer. A second series of measurements, making use of larger incidence angles (up to $5^{\circ}$ ) and a $0.6 \mathrm{~mm}$ beam slit was, therefore, used to estimate oxide thickness by probing the major base alloy peak between $2 \theta=49$ and $52.5^{\circ}$.

\section{X-Ray Photoelectron Spectroscopy (XPS)}

The composition of each corrosion specimen was investigated as a function of depth by successively removing surface material by argon ion bombardment and analyzing the freshly uncovered surface by XPS. This analysis was performed using a Physical Electronics Model 5601 Microfocus ESCA (Electron Spectroscopy for Chemical Analysis) system. The spectrometer employed a monochromated aluminum $X$-ray source $(E=1486.6 \mathrm{eV})$. Argon ion sputtering was performed with a differentially pumped ion gun operated at a beam voltage of $4 \mathrm{keV}$ with current densities in the range 32 to 40 $\mu \mathrm{A} / \mathrm{cm}^{2}$ using a $3 \times 3 \mathrm{~mm}$ raster. The ion beam was oriented approximately $60^{\circ}$ from the sample normal. To minimize shadowing and sputter-induced micro-feature formations that degrade depth resolution, the sample was rotated at 1 revolution per minute during sputtering. XPS analyses were taken from a circular area $800 \mu \mathrm{m}$ diameter in the center of the $3 \mathrm{~mm}$ diameter sputter crater. 
Sputter time was converted to sputter depth by multiplying the time by an experimentally derived sputter rate. This rate was determined by conducting periodic depth profiling experiments on a silicon dioxide $\left(\mathrm{SiO}_{2}\right)$ sputter standard known to have an oxide thickness of $1000 \AA$; its oxide thickness being independently confirmed by profilometry. For general purpose work, the relative differences in sputtering rates between $\mathrm{SiO}_{2}$ (or $\mathrm{Ta}_{2} \mathrm{O}_{5}$ ) and the transition metal oxides are estimated assuming that the sputter yield (i.e., atoms per argon ion) is independent of metal oxide. Since sputter rate is related to sputter yield by a specific grouping of physical properties, $\rho n / M(\rho$ is the oxide density, $n$ is the number of atoms per molecule and $\mathrm{M}$ is the molecular weight) [6], sputtering rates relative to $\mathrm{Ta}_{2} \mathrm{O}_{5}$ are readily determined. On this basis, typical corrosion oxide spinels $\mathrm{Fe}_{3} \mathrm{O}_{4}\left(0.157 \mathrm{~g}\right.$-atoms $\left.\mathrm{cm}^{-3}\right)$ and $\mathrm{FeCr}_{2} \mathrm{O}_{4}\left(0.155 \mathrm{~g}\right.$-atoms $\left.\mathrm{cm}^{-3}\right)$ will sputter at rates within $20 \%$ of the rate for $\mathrm{Ta}_{2} \mathrm{O}_{5}(0.130 \mathrm{~g}$-atoms $\left.\mathrm{cm}^{-3}\right)$.

In addition to the above mass-related effect, sputter yield can be decreased by surface roughness, shadowing and crystal face orientation effects. The combined effects of such phenomena were determined for an air-formed, spinel oxide corrosion film on a $20 \mathrm{Cr} 25 \mathrm{Ni}$ steel surface [7]. Based on independent determinations of oxide thickness, obtained via cross-sectioned metallographic mounts and confirmed by measured weight gains, the argon ion sputtering rate for corrosion oxide spinels is equal to that of the $\mathrm{Ta}_{2} \mathrm{O}_{5}$ sputtering rate divided by a factor of 1.85 .

Surface atomic compositions at each depth were derived by applying MultiPack $^{\mathrm{TM}}$, a software package developed by Physical Electronics for interpreting XPS data acquired on their instruments. This software facilitated data analysis by means of two pre-processing steps: (1) the Savitzky-Golay smoothing algorithm [8], based on a 7-point running average, suitably modified for end points, was applied to reduce spectral noise, and (2) a Shirley [9], integrated background correction was obtained 
by successive iterations to minimize interference caused by the inelastic scattering of low energy electrons. The pre-processed data in each element region was then integrated to obtain peak areas, which when multiplied by sensitivity factors, provided surface atom densities. The results were then normalized to obtain units of surface atom percent.

Sensitivity factors were obtained by calibration versus a copper standard and adjusted internally by MultiPack. This methodology allowed the software to account for specific hardware characteristics, i.e., the energy-dependent transmission characteristics of the specific analyzers and the angle between $\mathrm{X}$-ray source and analyzer. An independent check on the accuracy of the instrumental activity factors was provided by an XPS analysis of an unoxidized stainless steel specimen; the indicated composition was virtually identical to the chemical assay.

A change in oxidation state of an element is known to shift energies of its core electrons sufficiently so that it becomes possible to extract information on oxidation state by suitable spectral deconvolution of XPS data. Although chemical state identification is a distinct advantage of XPS, data interpretation can be difficult when XPS is used in conjunction with ion beam sputtering in depth profiling experiments. Ion beams are known to reduce some oxides to suboxides or even to metals [10-12], so an overly simplistic interpretation of the chemical shift of an XPS spectrum in a depth profiling experiment may lead to incorrect conclusions. To allow for this effect, a constrained least-squares analytical technique, known as target factor analysis (TFA) [13], was used to deconvolute the pre-processed XPS data.

After selecting a given energy region for chemical state speciation, i.e., the chromium $2 \mathrm{p}$ region (570$590 \mathrm{eV}$ ), the principal component analysis (PCA) routine is invoked to run mathematical tests on the data and determine the number of 'principal' components that may be present. The PCA is performed 
on all spectra of a given sample taken at different sputter depths. Depending on the number of principal components identified, a set of synthetic spectra ('eigen spectra') is generated from the PCA and the pre-processed data. In the case of chromium, for example, two eigen spectra were identified: one corresponding to $\mathrm{Cr}(0)$ and one to $\mathrm{Cr}(\mathrm{III})$. The target factor analysis (TFA) routine is then called to deconvolute each spectrum, by linear least squares regression, into a linear combination of the eigen spectra ('target' spectra). These linear fractions of the eigen/target spectra at each depth provide profiles of the indicated speciation in chemical state.

Some flexibility is permitted in the MultiPak software to determine the number of eigen spectra, thus the number of chemical states, that are contained within the raw data. Subjective tests are applied to the target solutions by the operator to determine that a given target component is significant (real signal) or insignificant (random noise). Experience with TFA has shown that optimal results are obtained when the surface has been sputtered to a depth sufficient to remove all oxygen. This technique ensures that an eigen spectrum truly representative of the metallic state will be obtained.

Physical interpretation of a given eigen spectrum by the analyst may also lead to several areas of subjectivity. For example, a sputter-damaged compound may display an eigen spectrum unique from the unsputtered compound. This happens to be the case in this work, where two Ni(2p) eigen spectra have been associated with the same Ni(II) compound; one component sputter damaged and the other not. These components were added together to represent the total Ni(II) concentration. The case of iron is even more complex because two non-zero oxidation states exist: $\mathrm{Fe}$ (II) and $\mathrm{Fe}$ (III), and both may become sputter-damaged. This complication was addressed by assuming that the corrosion oxide existed only as spinel compounds: $\mathrm{AB}_{2} \mathrm{O}_{4}$. Here $A$ refers to a divalent metal ion: $\mathrm{Ni}(\mathrm{II})$ or $\mathrm{Fe}(\mathrm{II})$; and 
$\mathrm{B}$ is a trivalent metal ion: $\mathrm{Cr}(\mathrm{III})$ or $\mathrm{Fe}(\mathrm{III})$. This assumption is justified because the GIXRD results established the sole presence of spinel and alloy substrate. No XRD lines remained unidentified.

An internal consistency check on the resulting speciation in oxidation states may be obtained by summing the (inferred) oxygen bonded to the (measured) oxidized metal species and comparing the result to the measured $O(1 \mathrm{~s})$ signal. Because oxygen is less massive than the transition metal elements, it tends to sputter preferentially [14], so that the $O(1 \mathrm{~s})$ signal was always greater (by a small amount) than the oxygen accounted for by summing the oxidized metal species.

The above caveats are mentioned because the combined XPS/ion milling/TFA methodology is rather recent and has not yet been widely applied to corrosion analyses. However, by applying the above consistency checks at various stages of the analysis, it becomes possible to provide accurate chemical state speciations versus sputter depth. The resulting profiles were then integrated versus depth to provide an independent, in-situ method for quantifying the amount, and distribution, of oxidized metals in the corrosion oxide layer.

\section{Chemical Descale}

Triplicate corrosion coupons were descaled using a two-step alkaline permanganate/ammonium citrate process: (l) $1 \% \mathrm{KMnO}_{4}$ and $5 \% \mathrm{NaOH}$ for 30 min. at $90^{\circ} \mathrm{C}$, followed by wiping and (2) $5 \%\left(\mathrm{NH}_{4}\right)_{2}$ citrate for $30 \mathrm{~min}$. at $90^{\circ} \mathrm{C}$. This method involved multiple applications and a reverse extrapolation to correct for base metal losses during corrosion oxide removal, per ASTM procedure G1-67. A minimum of four and a maximum of seven process applications were performed. 


\section{$\underline{\text { RESULTS }}$}

\section{A. SEM/EDX}

Appearances of the corroded 304 stainless steel specimens corresponding to exposure times between 1000 and 10,000 hours are shown in Fig $1(5000 \mathrm{X})$. It is seen that initial exposure resulted in the formation of a uniform coating of small, polyhedral crystals ranging in size between 0.1 and $0.5 \mu \mathrm{m}$. Interspersed intermittently on top of the base layer were larger, micron-sized crystals. Both crystal types were oriented in a manner which gave the appearance that they grew out of the original surface, or had crystallized from solution. This observation is supported by increases in crystal size and density with exposure time. After 5000 hours, the larger, micron-sized crystals exhibited overlapping growth, see Fig. 1 .

EDX analyses of the corrosion oxide crystals confirmed the expected presence of oxygen, iron, chromium, nickel and manganese. More importantly, the oxygen levels present in the larger, micronsized crystals were consistent with levels expected for spinel oxides $\left(\mathrm{AB}_{2} \mathrm{O}_{4}\right)$. Therefore, it was possible to infer a spinel oxide composition of the larger crystals by means of a material balance, assuming that chromium was present as $\mathrm{Cr}(\mathrm{III})$ and nickel as $\mathrm{Ni}(\mathrm{II})$.

TABLE I summarizes the EDX results obtained for the micron-sized oxide crystals from two 5000 hour corrosion specimens. The oxide crystals are seen to be a non-stoichiometric nickel ferrite $\left(\mathrm{Ni}_{0.15} \mathrm{Fe}_{0.85}\right) \mathrm{Fe}_{2} \mathrm{O}_{4}$ that contains less than 5 atom \% chromite. Unfortunately, spinel compositions for the sub-micron sized crystals could not be determined, due to low oxygen levels. The latter result indicates a significant contribution from the base alloy (stainless steel) to the EDX signal. 


\section{B. Grazing Incidence X-Ray Diffraction}

Full scan GIXRD patterns, obtained for two 10,000 hour specimens (S69, S41) are shown in Fig. 2 for $\phi$ (grazing incidence angle $)=1^{\circ}$. All measured peaks correspond to those of a spinel oxide, $\mathrm{AB}_{2} \mathrm{O}_{4}$. With the exception of unoxidized 304 stainless steel detected in scans at larger $\phi$, no other crystalline phases were detected. In order to obtain accurate estimates of unit cell dimensions for the spinel oxide phase, peak locations were obtained by applying a profile fitting procedure in which the Pearson VII function was fitted to each peak. Further corrections to account for changes in index of refraction were not necessary because at $\phi=1^{\circ}$, the correction is negligible $\left(<0.001^{\circ}\right)$. The results of these analyses for $\phi=1^{\circ}$ are given in TABLE II. Unit cell parameters were determined from the observed peak positions by least squares refinement.

Lattice parameters for the two specimens were identical within the refinement errors. The approximate stoichiometry of the spinel oxide, consistent with previous SEM/EDX analyses which indicated that $\mathrm{A}=\mathrm{Fe}, \mathrm{Ni}$ and $\mathrm{B}=\mathrm{Fe}$ in the spinel formula $\mathrm{AB}_{2} \mathrm{O}_{4}$, was estimated assuming that lattice parameter varied linearly with $\mathrm{Ni}$ content. The appropriate end-member values for $\mathrm{Fe}_{3} \mathrm{O}_{4}$ and $\mathrm{NiFe}_{2} \mathrm{O}_{4}$ are $8.3967 \AA$ (PDF card 19-629) and $8.339 \AA$ (PDF card 10-325), respectively. Based on the measured lattice size $(8.387 \AA)$, the estimated stoichiometry $\left(\mathrm{Ni}_{0.17} \mathrm{Fe}_{0.83}\right) \mathrm{Fe}_{2} \mathrm{O}_{4}$ is in good agreement with the SEM/EDX results.

Thicknesses of the spinel oxide corrosion layer were estimated by monitoring for the emergence of the base alloy [200] peak at several incident angles from $\phi=0.5$ to $5^{\circ}$. The diffraction patterns observed for consecutive low angle measurements on both 10,000 hour specimens are shown in Figs. 3 and 4 . The expected relationship between penetration depth $(t)$ and angle of incidence ( $\phi$, radians) is described by absorption: 


$$
I / I_{o}=\exp (\mu t / \sin \phi)
$$

where $\mu$ is the linear absorption coefficient. If we consider $\mathrm{l} / \mathrm{I}_{0}=0.05$ to be a practical attenuation limit, the estimated penetration depth for thick corrosion films becomes $t=3 \phi / \mu$. Applying the given formula with $\mu$ expected at $\lambda=1.542 \AA$ (i.e., $1162.05 \mathrm{~cm}^{-1}$ for $\mathrm{Fe}_{3} \mathrm{O}_{4}$ ), results in estimated penetration depths of $0.45 \mu \mathrm{m}$ for $1^{\circ}$ and $1.80 \mu \mathrm{m}$ for $4^{\circ}$.

As shown in Figs. 3 and 4, base alloy is first detected at an incident angle of $3^{\circ}$, providing an estimated thickness of $1.3 \mu \mathrm{m}(13,000 \AA)$. It is believed that this thickness is representative of the oxide underneath the large, outer layer crystals $(5-10 \mu \mathrm{m})$, since the SEM results demonstrate that the large crystals form an incomplete surface coverage.

\section{X-Ray Photoelectron Spectroscopy with Argon Ion Milling}

Typical elemental composition versus depth profiles are shown in Figs. 5a and b for specimens having exposure times of 5000 and 10,000 hours, respectively. As expected, the major elements detected were oxygen, iron, chromium and nickel. Significant levels of carbon were also found on the surfaces of all specimens. Because the initial ion milling operation reduced the carbon signals to approximately that of the base alloy (i.e., $\sim 0.1 \%$ ), the carbon was concluded to be present as an adsorbed layer of hydrocarbon contamination, and was neglected when performing further analyses.

The presence of outer layer corrosion oxides, i.e., the observed polyhedral crystals, growing on the specimen surfaces in Fig. 1, tended to manifest themselves by causing elongated 'tails' in the oxygen profiles, see Fig. 5. Therefore, estimates of oxide thickness were obtained from the inflection point in each oxygen profile: a maximum in the first derivative represents the depth at which ion milling of the 
oxide layer exposed metal substrate at the most rapid rate. These results are summarized in TABLE III. For consistency with the expected corrosion kinetics, increases in oxide thickness were correlated with a parabolic growth rate law:

$$
O(1 s)=k_{p}(t+P F)^{1 / 2}
$$

where $\mathrm{PF}=500 \mathrm{hrs}$ for the PF-designated specimens. By least-squares analysis, it was found that $\mathrm{k}_{\mathrm{p}}=$ $460 \pm 30 \AA \mathrm{hr}^{-1 / 2}$. Assuming an oxide density of $5.2 \mathrm{~g} \mathrm{~cm}^{-3}$ converts the parabolic rate constant to 2.39 mg (spinel) $\mathrm{dm}^{-2} \mathrm{hr}^{-1 / 2}$.

The above oxide thickness estimates were refined and speciated by TFA; speciated profiles for the 5000 and 10,000 hr specimens are being shown in Figs. 6 and 7, respectively. To facilitate oxide comparisons, two plots were generated for each speciated composition profile: (a) a color-coded split between oxidized metal and unoxidized metal, and (b) the indicated stoichiometry of the spinel oxide $\left(\mathrm{Ni}_{\mathrm{y}} \mathrm{Fe}_{1-\mathrm{y}}\right)\left(\mathrm{Fe}_{2-\mathrm{x}} \mathrm{Cr}_{\mathrm{x}}\right)_{2} \mathrm{O}_{4}$. This information is summarized in a tabular manner and integrated numerically to quantify the overall amount and stoichiometry of the corrosion film, see TABLES IV and V. Regression of these values provides a parabolic rate constant of $1.76 \pm 0.33 \mathrm{mg}$ (metals) $\mathrm{dm}^{-2}$ $\mathrm{hr}^{-1 / 2}$.

The above results provide conclusive evidence that 304 stainless steel corrodes in a non-selective manner, since the metal ion composition of the corrosion oxide is the same as the metal composition of the alloy substrate. Two other characteristics of the corrosion oxide are noteworthy: (1) the Ni(II) and Fe(II) ion compositions are uniform (and the same) in the inner and outer oxide layers, and (2) the outer layer spinel consists nearly entirely of ferrite. 
A fourth finding, namely, that the inner oxide layer contains nearly equal amounts of $\mathrm{Cr}$ (III) and Fe(III), requires further qualification, since interference from the larger, outer layer ferrites tends to bias the determination of the $\mathrm{Cr}$ (III)-Fe(III) split in the inner layer. Since some of the outer layer oxide crystals are larger than the thickness of the inner layer, the indiscriminant argon ion etching process may encounter remnants of the outer layer (ferrite-based) crystals after most of the inner layer (chromite-based) crystals have been etched away. Such behavior is evident in Fig. 7 where maxima in $\mathrm{Cr}$ (III) versus depth profiles are noted; greater etch depths lead to increases in Fe(III) content, rather than decreases. To verify that this anomalous behavior is indeed an artifact of the sputtering process, major portions of the outer layer were mechanically removed on selected specimens by means of a pencil eraser.

Typical results of XPS/sputtering analyses on these surfaces are shown in Fig. 8. As expected, removal of interference from the larger, outer layer crystals led to higher, and more accurate, estimates of inner layer chromite content. The indicated spinel composition of the inner layer is $\left(\mathrm{Ni}_{0.2} \mathrm{Fe}_{0.8}\right)\left(\mathrm{Fe}_{0.3} \mathrm{Cr}_{0.7}\right)_{2} \mathrm{O}_{4}$. A material balance, performed using integrated, speciated composition profiles of the erased and non-erased areas, gives a spinel composition of $\left(\mathrm{Ni}_{0.26} \mathrm{Fe}_{0.74}\right)\left(\mathrm{Fe}_{0.89} \mathrm{Cr}_{0.11}\right)_{2} \mathrm{O}_{4}$ for the removed material. This composition is in good agreement with the outer layer composition given previously in TABLE $V$.

\section{Chemical Descale}

TABLE VI summarizes the amounts of corrosion (and release) measured on the larger-size coupons $\left(0.4078 \mathrm{dm}^{2}\right.$ per coupon) exposed simultaneously with the smaller, polished specimens. In aqueous systems, the difference between the amount of corrosion (i.e., corrosion film creation) and the buildup of a corrosion film needs to be considered due to the possibility of oxide loss by dissolution and/or 
sloughage into the aqueous phase. Since the corrosion of 304 stainless steel in aqueous media is manifested by the formation of a dominant, hydrothermally-grown outer corrosion layer on top of a diffusion-grown inner layer, it is expected that the water condition (with respect to saturation concentrations of the soluble metal ions) will affect the quantity of outer layer. Therefore, it is not obvious whether a corroding specimen will gain or lose weight upon testing.

It is possible, however, to bracket potential weight changes from measured corrosion rates on the basis of two limiting cases: (a) zero release and (b) complete release. In the case of zero release, i.e., complete retention:

final wgt. $=$ pretest wgt. + oxygen in cor. oxide

Since the metal oxides formed during the corrosion process are known to be spinels, $\mathrm{MFe}_{2} \mathrm{O}_{4} / \mathrm{MCr}_{2} \mathrm{O}_{4}$, whose average oxygen content is $27.9 \pm 0.6$ wgt. $\%$, the zero release case becomes

$$
\text { final wgt. }=\text { pretest wgt. }+0.387 \text { (metals oxidized) }
$$

In the case of complete release:

$$
\text { final wgt. }=\text { pretest wgt. }- \text { (metals oxidized) }
$$

By expressing the post-test weight - pre-test weight difference as a fraction of the maximum change between the zero and complete release limiting cases, i.e., $1.387 \times$ metals oxidized, the fraction of corroded alloy released to the coolant was determined.

Because only a minor fraction of the corrosion oxide film was released to the water $(\sim 1 \%)$, the apparent $40 \%$ discrepancy in parabolic rate constants between the gravimetric and XPS/ion milling 
analyses, i.e., $1.16 \pm 0.05 \mathrm{mg}$ (metals) $\mathrm{dm}^{-2} \mathrm{hr}^{1 / 2}$ and $1.76 \pm 0.33 \mathrm{mg}$ (metals) $\mathrm{dm}^{-2} \mathrm{hr}^{1 / 2}$, was reconciled by re-examining the methodology on which the argon ion sputtering rate was based. A portion of the 10,000-hour specimen (S67) was tungsten-coated and mounted for metallographic examination. A polished cross-sectional cut of the mount, when viewed on the SEM, permitted a direct measurement of oxide thickness, see Fig. 9. Note that all three interfaces are well-defined: alloy/inner layer, inner layer/outer layer and outer layer/tungsten. Due to the high degree of surface 'roughness', i.e., nonuniformity, caused by the presence of individual outer layer crystals, thickness was obtained by averaging more than fifty equally-spaced measurements along the surface. In this manner, it was found that $\mathrm{t}=3.24 \pm 1.36 \mu \mathrm{m}$. Note that the inner layer oxide thickness $(1-2 \mu \mathrm{m})$ compares well with that estimated by GIXRD.

Based on the calibrated sputter rate through a $\mathrm{Ta}_{2} \mathrm{O}_{5}$ standard, the corresponding $\mathrm{Ta}_{2} \mathrm{O}_{5}$ thickness is 8.5 $\mu \mathrm{m}$, giving a revised calibration factor for corrosion oxide films formed in aqueous media as 2.62 $(+2.64 /-0.77)$. This result suggests that the previous calibration factor, derived for air-formed films (1.85), over-estimated the sputter rate by about $40 \%$ and that the XPS-estimated parabolic rate constant should be closer to $1.24 \mathrm{mg}$ (metals) $\mathrm{dm}^{-2} \mathrm{hr}^{-1 / 2}$. Thus, the parabolic rate constants determined by gravimetric and in-situ XPS are in agreement.

As followup to the SEM/EDX results presented previously, Fig. 10 provides color-coded elemental Auger intensity maps for $\mathrm{Fe}, \mathrm{Ni}, \mathrm{Cr}, \mathrm{O}$ and $\mathrm{W}$ in a cross-sectional area of the corrosion film shown in Fig. 9. The uniformity of composition of the inner and outer layers is particularly noteworthy: the Fe map shows a sharp transition between the outer and inner layers, while the $\mathrm{Cr}$ map reinforces this result and also indicates the absence of $\mathrm{Cr}$ in the outer layer oxide. The $\mathrm{O}$ map confirms that the identified inner and outer layers are indeed oxides, while the Ni map indicates approximately equal 
concentrations of nickel in the inner and outer layers. These compositional details are entirely consistent with, and provide validation of, the proposed two-layer model of the corrosion film.

\section{SUMMARY/CONCLUSIONS}

The corrosion behavior of an austenitic stainless steel (UNS S30400) has been characterized in hydrogenated, ammoniated water at $260^{\circ} \mathrm{C}$ using a combination of complementary analytical techniques: scanning electron microscopy (with energy dispersive $\mathrm{X}$-ray spectroscopy), grazing incidence X-ray diffraction, $\mathrm{X}$-ray photoelectron spectroscopy (with argon ion milling and target factor analysis) and gravimetric descale analysis. Based on exposure times up to 10,000 hours, the corrosion kinetics were observed to follow a parabolic rate expression given by $W\left(m g\right.$ alloy $\left.\mathrm{dm}^{-2}\right)=1.16 \mathrm{t}^{1 / 2}(\mathrm{t}$ in $\mathrm{hr}$ ). Values of the parabolic rate constant obtained by gravimetric analysis and XPS/ion milling were found to be the same, within experimental error. More importantly, however, the XPS/TFA results determined the distribution of the three oxidized alloying constituents $(\mathrm{Fe}, \mathrm{Cr}, \mathrm{Ni})$ with respect to depth and elemental state. These speciated composition profiles were integrated over depth and shown to provide an oxidized metal composition of the corrosion film that was identical to the elemental distribution in 304 stainless steel. This result indicates that corrosion occurs non-selectively.

A cross-sectioned metallographic mount of the corroded surface provided striking visual evidence of two significant features of the corrosion film: (a) the surface oxide layer is greatly roughened by the presence of individual oxide crystals having a size range between 5 and $10 \mu \mathrm{m}$, and (b) a second oxide phase exists beneath the outer layer crystals.

Grazing incidence X-ray diffraction identified the crystalline lattice configuration of the corrosion oxide to be that of a spinel: $\mathrm{AB}_{2} \mathrm{O}_{4}$, where $\mathrm{A}$ represents a divalent cation and $\mathrm{B}$ represents a trivalent 
cation. No other oxide phases were detected. In the outer layer, $\mathrm{Fe}(\mathrm{III})$ was found to be the main $\mathrm{B}$ constituent by XPS, while both $\mathrm{Cr}(\mathrm{III})$ and $\mathrm{Fe}(\mathrm{III})$ were present in the inner layer.

The outer layer formed on top of the original alloy surface, and grew outwards, probably by a recrystallization process. The resulting crystals exhibited well-defined polyhedral shapes and had the approximate size range $1-10 \mu \mathrm{m}$. They form a rather porous and loosely-adherent layer. Their chemical composition is uniform and the spinel is nearly entirely ferrite, the B component being less than $5 \mathrm{~mol} \% \mathrm{Cr}$. The divalent cations were mainly Fe(II), $80 \mathrm{~mol} \%$, with $20 \mathrm{~mol} \% \mathrm{Ni}(\mathrm{II})$. The resulting stoichiometry, $\left(\mathrm{Ni}_{0.2} \mathrm{Fe}_{0.8}\right)\left(\mathrm{Fe}_{0.95} \mathrm{Cr}_{0.05}\right)_{2} \mathrm{O}_{4}$, was confirmed by SEM/EDX, XRD (lattice parameter) and XPS/TFA.

The inner layer formed by growing into the original alloy surface. The resultant spinel crystals are much smaller, i.e., size range 0.005 to $0.01 \mu \mathrm{m}$. They form a non-porous, tightly adherent layer. The composition of this layer is also uniform and does not change with depth. The divalent cation split is about the same as in the outer layer: $80 \mathrm{~mol} \% \mathrm{Fe}(\mathrm{II})$ and $20 \mathrm{~mol} \% \mathrm{Ni}(\mathrm{II})$. On the other hand, the B component is dominated by $\mathrm{Cr}(\mathrm{III})$. Considerable difficulty was encountered when determining the actual $\mathrm{Cr}(\mathrm{III})-\mathrm{Fe}$ (III) split, since the intermittent nature of the outer layer tended to bias the argon ion sputtering process used to measure these concentrations. However, by mechanically removing the outer layer crystals prior to analysis, it was found that the inner layer B-cation content was $70 \mathrm{~mol} \%$ $\mathrm{Cr}(\mathrm{III})$ and $30 \mathrm{~mol} \% \mathrm{Fe}(\mathrm{III})$, giving the stoichiometric formula as $\left(\mathrm{Ni}_{0.2} \mathrm{Fe}_{0.8}\right)\left(\mathrm{Cr}_{0.7} \mathrm{Fe}_{0.3}\right)_{2} \mathrm{O}_{4}$.

The significance of the above compositions lies in its suggested connection to spinel immiscibility. Although both outer and inner oxide layers are spinels, the ferrite-based outer layer is an inverse spinel while the chromite-based inner layer is a normal spinel [15]. This distinction is important because, 
when an alloy (which represents a single phase, solid solution of elemental metals) undergoes oxidation, one would expect that a single phase oxide (i.e., spinel) would be capable of accommodating the oxidized alloying constituents in a solid solution. However, the existence of two spinel subcategories imposes certain limitations on the mixing process. For example, solid solutions of inverse spinels are nearly ideal, as are solid solutions of normal spinels [16]. On the other hand, solid solutions of normal and inverse spinels are non-ideal and may not mix completely in all proportions. The $\mathrm{Fe}_{3} \mathrm{O}_{4-}$ $\mathrm{FeCr}_{2} \mathrm{O}_{4}$ binary, which is relevant to spinel corrosion films on iron-based $\mathrm{FeCrNi}$ alloys, is known to exhibit a consolute solution temperature around $880^{\circ} \mathrm{C}$ [17]. Below this temperature, complete mixing is not possible and separation into a ferrite-rich spinel and a chromite-rich spinel occurs. Compositions of the two immiscible phases (known as solvi) change slightly with temperature, but are estimated to be around $\mathrm{Fe}\left(\mathrm{Fe}_{0.85} \mathrm{Cr}_{0.15}\right)_{2} \mathrm{O}_{4}$ and $\mathrm{Fe}\left(\mathrm{Fe}_{0.35} \mathrm{Cr}_{0.65}\right)_{2} \mathrm{O}_{4}$ at $260^{\circ} \mathrm{C}$ [17]. This result is identical within experimental error, to the $\mathrm{Fe}$ (III)-Cr(III) distribution observed in the corrosion oxide layers formed on 304 stainless steel. Given this connection between spinel immiscibility and the formation of inner and outer layer spinel oxides on corroding $\mathrm{NiCrFe}$ alloys, it may be prudent to re-examine previous corrosion models proposed for $\mathrm{NiCrFe}$ alloys.

\section{ACKNOWLEDGEMENT}

The professional assistance of the following individuals is gratefully acknowledged: Dr. Y. Gao (grazing incidence XRD, General Electric Co. CR\&D Center), Dr. H. M. Tunison (chemical descale analysis) and G. M. Neugebauer (SEM/EDX). 


\section{REFERENCES}

1. H.-J. Eckstein, Stahlberatung 13, 6 (1986)

2. E. Maurer and B. Strauss, Reichspatente Nr. 304126 and 304159 (1912)

3. D.H. Lister, R.D. Davidson and E. McAlpine, Corros. Sci. 27, 113 (1987)

4. Z. Szklarska-Smialowska, K. C. Chou and Z. Xia, Corros. Sci. 32, 609 (1991)

5. J. Robertson, Corrosion Science 32, 443 (1991)

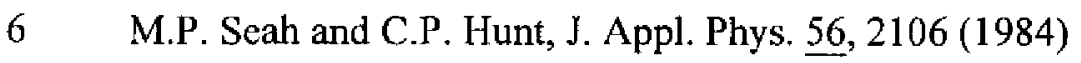

7. R.K. Wild, Surf. Interface Anal. 14, 239 (1989)

8. A. Savitzky and M.J.E. Golay, Anal. Chem. 36(8), (1964)

9. D.A. Shirley, Phys. Rev. B5, 4709 (1972)

10. .M. Ostyn and C.B. Carter, Surface Sci. 121, 360-374 (1982).

11 M.A. Langell, Surface Sci. $186,323-338$ (1987)

12 A.R. Gonzalez-Elipe, R. Alvarez, J.P. Espinos and G. Munuera, Applied Surface Sci. 51, 19-26 (1991)

13. E.R. Malinowski, Factor Analysis in Chemistry, John Wiley \& Sons, NY (1991)

14. L.I. Yin, S. Ghose and I. Adler, Appl. Spectrosc. 26, 355 (1972)

15. H. St. C. O'Neill and A. Navrotsky, Amer. Mineral. $\underline{68}, 181$ (1983)

16. H. St. C. O'Neill and A. Navrotsky, Amer. Mineral. $\underline{69}, 733$ (1984)

17. V. Cremer, N. Jb. Miner. Abh. 111, 184 (1969) 
TABLE I

Composition of Micron-Sized Oxide Crystals

Formed on 304 Stainless Steel

\begin{tabular}{|c|c|c|c|c|}
\hline \multirow{2}{*}{$\begin{array}{c}\text { Specimen/ } \\
\text { Exposure hrs }\end{array}$} & \multicolumn{3}{|c|}{ Atom \%, Normalized } & Inferred Spinel \\
Composition
\end{tabular}




\section{TABLE I}

Indexed Spinel Oxide Diffraction Peaks Observed on Corroded 304 Stainless Steel Specimens by Grazing Incidence X-Ray Diffraction $\left(\phi=1^{\circ}\right)$

\begin{tabular}{ccc}
\hline $\begin{array}{c}\text { Reflection Plane } \\
\text { Indices, hkl }\end{array}$ & $\begin{array}{c}\text { S41* } \\
2 \ominus, \text { deg }\end{array}$ & $\begin{array}{c}\text { S69* } \\
2 \ominus, \text { deg }\end{array}$ \\
\hline 111 & 18.282 & 18.289 \\
220 & 30.092 & 30.102 \\
311 & 35.451 & 35.460 \\
222 & 37.072 & 37.101 \\
400 & 43.086 & 43.095 \\
422 & 53.487 & 53.477 \\
511 & 57.017 & 57.017 \\
440 & 62.609 & 62.625 \\
Lattice & $8.388(1)$ & $8.386(1)$ \\
parameter, $\AA$ & & \\
*10,000 hours exposure at $260^{\circ} \mathrm{C}$ &
\end{tabular}




\section{TABLE III}

Surface Oxide Layer Thickness of Type 304 Stainless Steel

Based on Intensity of O(1s) XPS Peak

\begin{tabular}{lcc}
$\begin{array}{l}\text { Exposure } \\
\text { Time, hrs }\end{array}$ & O(1s) Depth, $\AA$ & $\mathrm{PF}^{*}$ \\
\hline 1000 & 9730 & 14900 \\
2000 & 16490 & 21600 \\
5000 & 21080 & 28000 \\
5000 & 40540 & 42200 \\
8000 & 32430 & 57300 \\
10,000 & 45140 & 48300
\end{tabular}

* All PF specimens received 500 hrs additional exposure prior to start of testing. 
TABLE IV

304 Stainless Steel Corrosion Film Characterization by Integration of Speciated Composition Profiles

\begin{tabular}{|c|c|c|c|c|}
\hline \multirow{2}{*}{$\begin{array}{c}\text { Exposure Time, } \\
\text { hrs }\end{array}$} & \multirow{2}{*}{$\begin{array}{l}\text { Metal Ion Content } \\
\mathrm{mg} / \mathrm{dm}^{2}\end{array}$} & \multicolumn{3}{|c|}{ Distribution, wgt\% } \\
\hline & & $\mathrm{Ni}$ & $\mathrm{Cr}$ & $\mathrm{Fe}$ \\
\hline $1000(\mathrm{~S} 85)$ & 54.7 & 8.2 & 20.9 & 70.9 \\
\hline $2000(\mathrm{~S} 81)$ & 68.1 & 8.7 & 21.4 & 69.8 \\
\hline $5000(\mathrm{~S} 75)$ & 97.2 & 10.0 & 22.2 & 67.8 \\
\hline 5000 (S99) & 167.4 & 7.9 & 15.9 & 76.2 \\
\hline 8000 (S93) & 143.9 & 3.3 & 24.2 & 72.5 \\
\hline $10,000(\mathrm{~S} 67)$ & 197.4 & 6.7 & 18.7 & 74.7 \\
\hline & avg & $7.5 \pm 2.1$ & $20.6 \pm 2.6$ & $72.0 \pm 2.8$ \\
\hline & $\mathrm{NiCrFe}$ in $304 \mathrm{SS}$ : & 8.6 & 19.0 & 72.4 \\
\hline
\end{tabular}




\section{TABLE V}

Spinel Composition $\left(\mathrm{Ni}_{\mathrm{y}} \mathrm{Fe}_{1-\mathrm{y}}\right)\left(\mathrm{Fe}_{2-\mathrm{x}} \mathrm{Cr}_{\mathrm{x}}\right)_{2} \mathrm{O}_{4}$ of

Surface and Inner Corrosion Layers on 304 Stainless Steel

\begin{tabular}{ccccc}
\hline $\begin{array}{c}\text { Exposure Time, } \\
\text { hrs }\end{array}$ & \multicolumn{2}{c}{ Surface Layer } & \multicolumn{2}{c}{ Inner Layer } \\
\hline $1000(\mathrm{~S} 85)$ & 0.2 & 0.2 & $y$ & $x^{*}$ \\
\hline 2000 (S81) & 0.2 & 0.2 & 0.3 & 0.9 \\
5000 (S75) & 0.2 & 0.2 & 0.3 & 0.9 \\
5000 (S99) & 0.2 & 0.0 & 0.25 & 0.9 \\
8000 (S93) & 0.1 & 0.0 & 0.2 & 0.7 \\
$10,000(\mathrm{~S} 67)$ & 0.2 & 0.0 & 0.1 & 1.1 \\
& & & 0.2 & 0.95 \\
& avg: $\left(\mathrm{Ni}_{0.2} \mathrm{Fe}_{0.8}\right)\left(\mathrm{Fe}_{0.95} \mathrm{Cr}_{0.05}\right)_{2} \mathrm{O}_{4}$ & $\left(\mathrm{Ni}_{0.2} \mathrm{Fe}_{0.8}\right)\left(\mathrm{Fe}_{0.55} \mathrm{Cr}_{0.45}\right)_{2} \mathrm{O}_{4}$
\end{tabular}

* Expected bias in result, see text for correction. 


\section{TABLE VI}

304 Stainless Steel Corrosion Estimates Obtained by Chemical Descaling

\begin{tabular}{|c|c|c|c|c|c|}
\hline $\begin{array}{c}\text { Exposure } \\
\text { hrs } \\
\text { (ID) } \\
\end{array}$ & $\begin{array}{l}\text { Total Corrosion } \\
\text { mg (metal) d }{ }^{-2}\end{array}$ & Avg & $\begin{array}{c}\text { Weight Change } \\
\text { During Test, } \\
\text { mg dm}\end{array}$ & $\begin{array}{c}\text { Zero Release } \\
\text { Wgt. Change, } \\
\text { mg dm } \\
\end{array}$ & $\begin{array}{c}\text { Corrosion } \\
\text { Release, } \\
\% \\
\end{array}$ \\
\hline $1000(19)$ & $39.14 \pm 0.17$ & & 15.11 & 15.14 & 0 \\
\hline $1000(21)$ & $38.43 \pm 0.34$ & & 14.91 & 14.87 & 0 \\
\hline $1000(23)$ & $40.19 \pm 0.25$ & $39.25^{*}$ & 15.03 & 15.55 & 0 \\
\hline $2000(13)$ & $51.86 \pm 0.37$ & & 19.62 & 20.07 & 1 \\
\hline $2000(15)$ & $51.32 \pm 0.12$ & & 20.01 & 19.86 & 0 \\
\hline $2000(17)$ & $51.94 \pm 0.17$ & $51.71^{*}$ & 20.30 & 20.10 & 0 \\
\hline $5000(7)$ & $85.14 \pm 0.27$ & & 32.34 & 32.95 & 1 \\
\hline $5000(9)$ & $84.28 \pm 0.44$ & & 32.66 & 32.62 & 0 \\
\hline $5000(11)$ & $83.30 \pm 0.37$ & $84.24^{*}$ & 32.96 & 32.24 & -1 \\
\hline $5000(31)$ & $80.92 \pm 2.13$ & & 29.21 & 31.32 & 2 \\
\hline $5000(33)$ & $83.35 \pm 0.34$ & & 28.94 & 32.26 & 3 \\
\hline $5000(35)$ & $76.16 \pm 1.25$ & $80.14^{* *}$ & 27.56 & 29.48 & 2 \\
\hline $8000(25)$ & $94.07 \pm 0.78$ & & 34.72 & 36.40 & 1 \\
\hline $8000(27)$ & $104.73 \pm 0.51$ & & 36.98 & 40.53 & 2 \\
\hline $8000(29)$ & $91.34 \pm 1.03$ & $96.71^{* *}$ & 30.90 & 35.35 & 4 \\
\hline $10,000(1)$ & $118.15 \pm 2.62$ & & 41.93 & 45.72 & 2 \\
\hline $10,000(3)$ & $117.61 \pm 1.62$ & & 41.32 & 45.51 & 3 \\
\hline $10,000(5)$ & $117.07 \pm 1.28$ & $117.61^{* *}$ & 42.55 & 45.31 & 2 \\
\hline
\end{tabular}

* Expected accuracy: $\pm 0.5 \%$

** $\pm 1.3 \%$ 
(a)

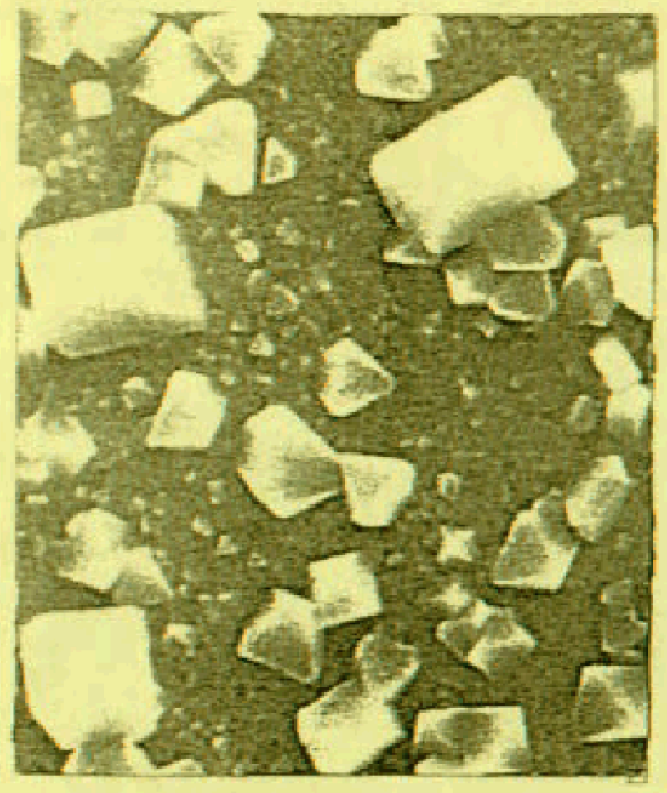

(b)

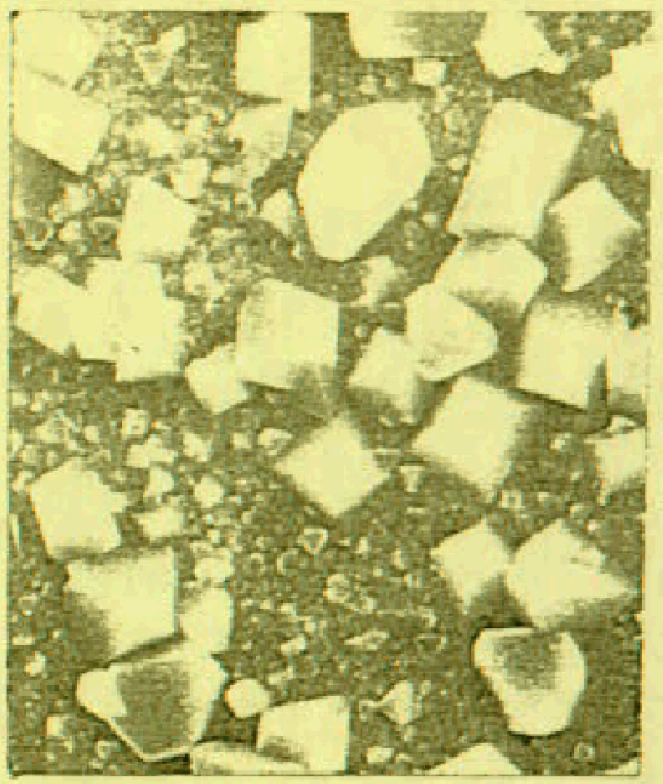

(c)

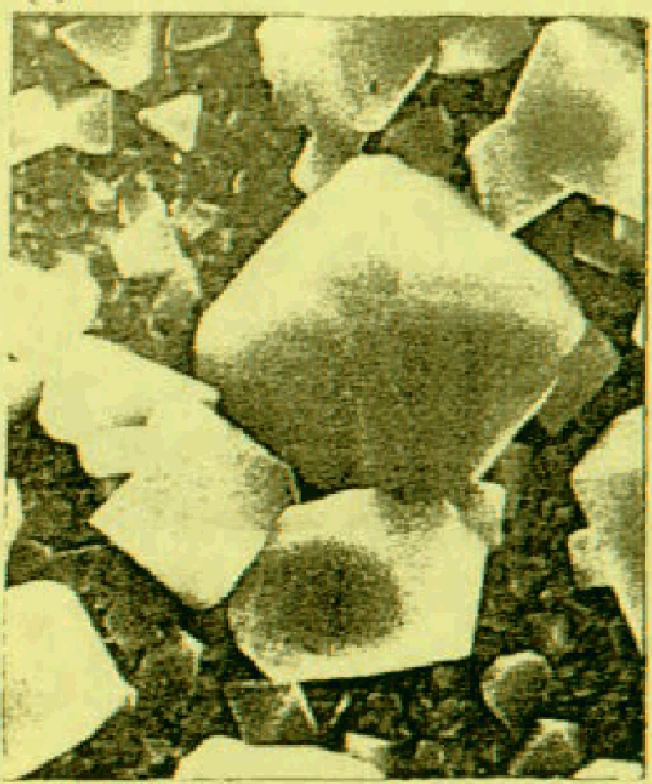

(d)

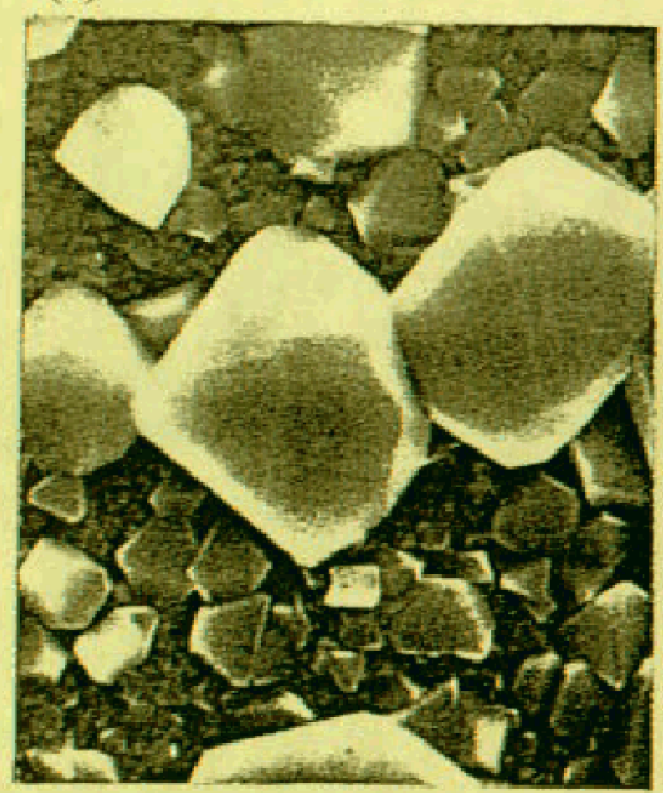

Fig. 1. High magnification SEM photographs of 304 stainless steel after exposure to high temperature hydrogenated, ammoniated water: (a) $1000 \mathrm{hr}$, (b) $2000 \mathrm{hr}$, (c) $5000 \mathrm{hr}$ and (d) $10,000 \mathrm{hr}$. 


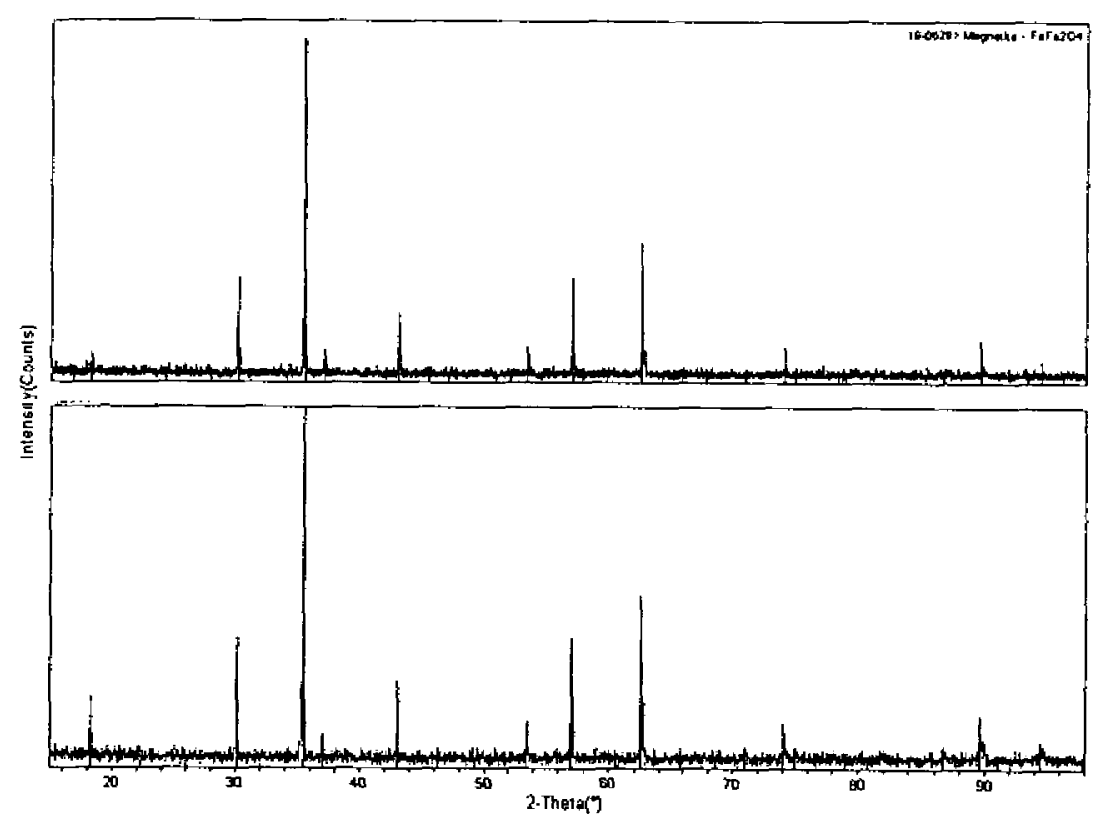

Fig. 2. Grazing incidence XRD patterns for two $10,000 \mathrm{hr}$ corrosion specimens $\mathrm{S} 4 \mathrm{l}$ (top) and $\mathrm{S} 69$ (bottom); full scan at $\phi=1^{\circ}$. All peaks can be identified as spinel phase, per comparison with PDF card 19-629 $\left(\mathrm{Fe}_{3} \mathrm{O}_{4}\right)$. 


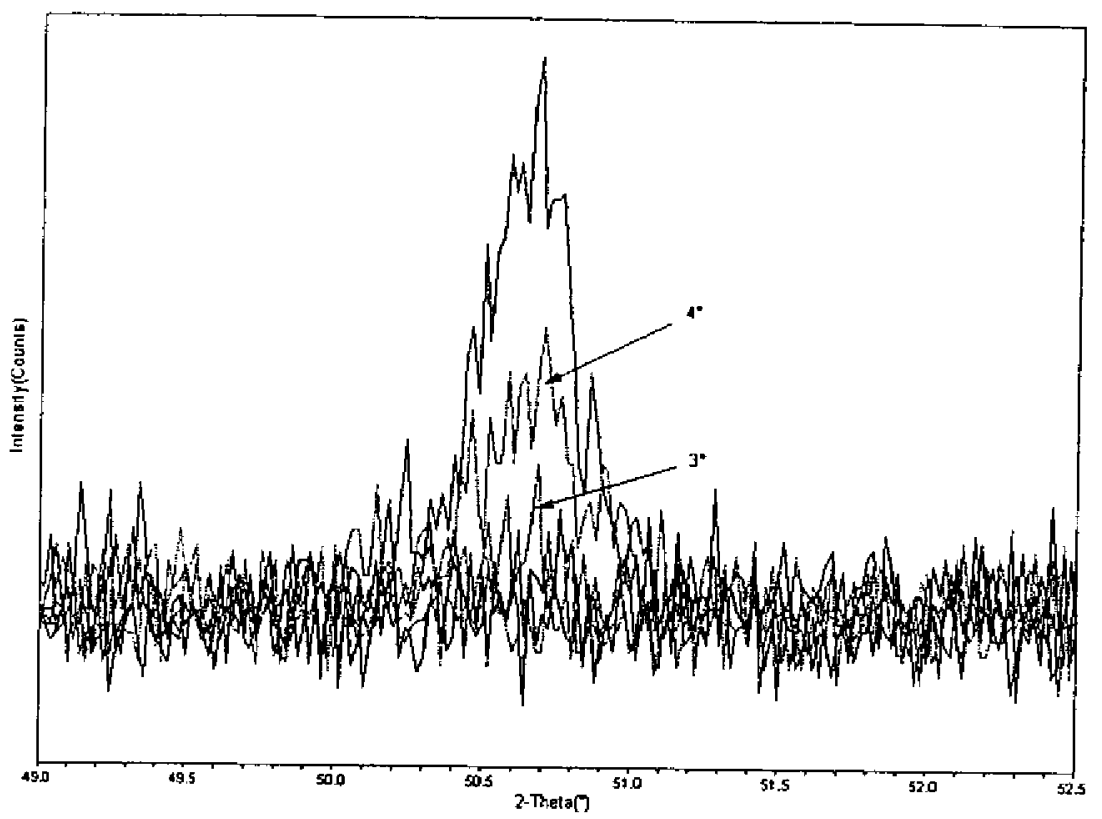

Fig. 3. Two-theta region of $10,000 \mathrm{hr}$ corrosion specimen (S41) in vicinity of base metal [200] peak at incidence angles between 1 and $5^{\circ}$. Note the appearance of base metal at $\phi=3^{\circ}(1.3 \mu \mathrm{m})$.

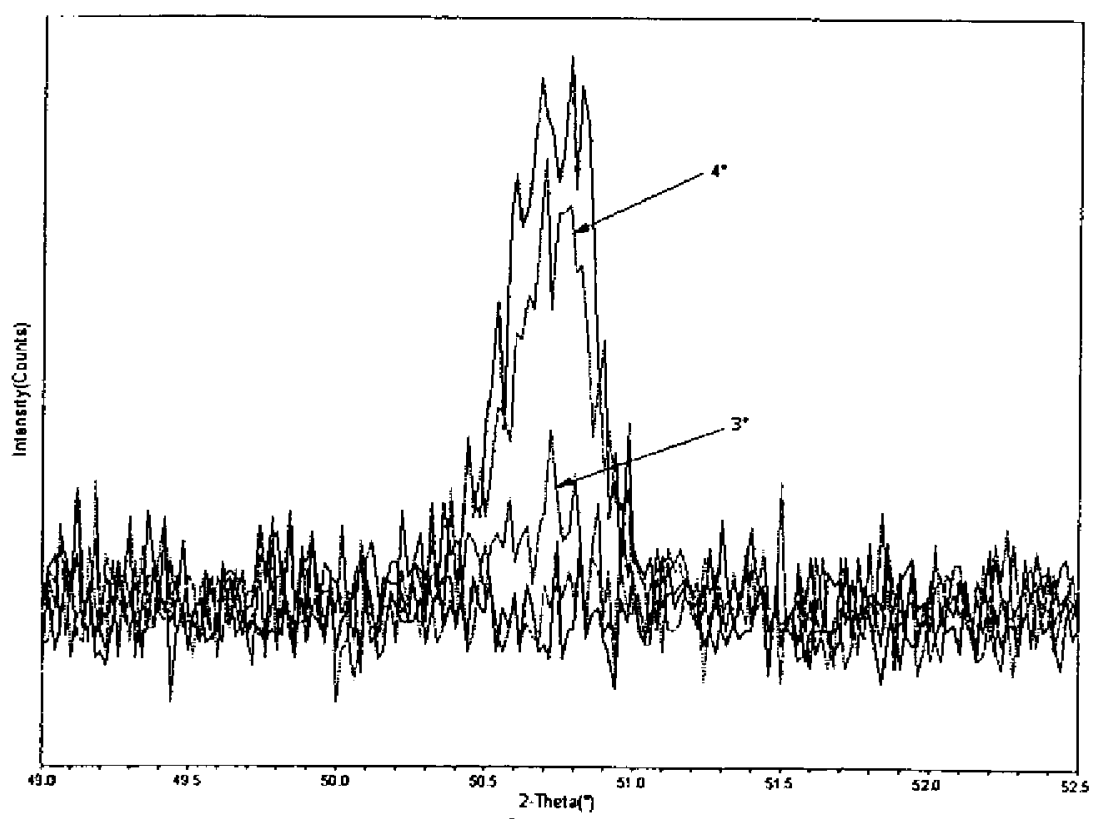

Fig. 4. Two-theta region of $10,000 \mathrm{hr}$ corrosion specimen (S69) in vicinity of base metal [200] peak at incidence angles between $1^{\circ}$ and $5^{\circ}$. Note appearance of base metal at $\phi=3^{\circ}(1.3 \mu \mathrm{m})$. 


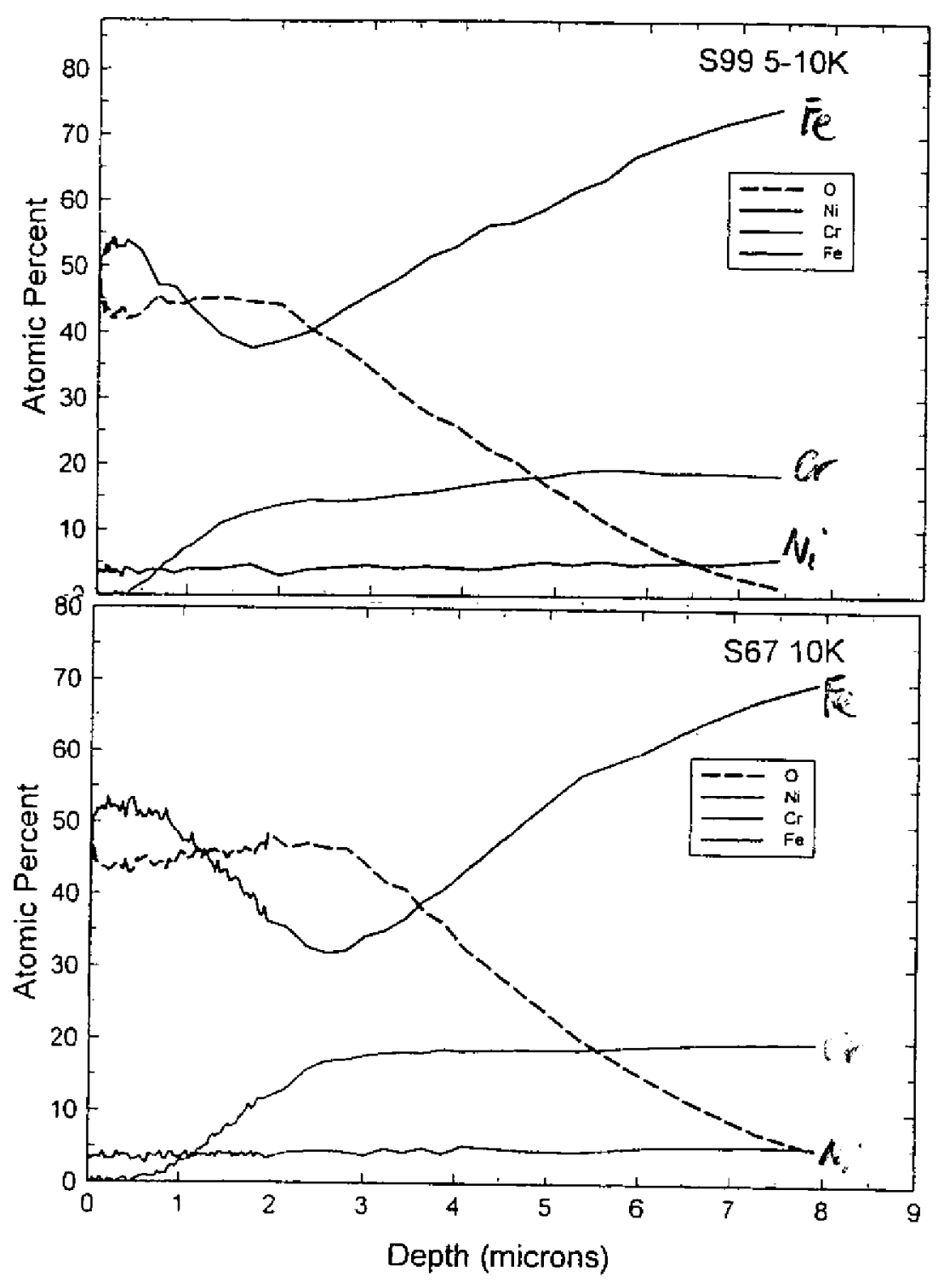

Fig. 5 Elemental composition versus depth profiles for 304 stainless steel specimens: (a) $5000 \mathrm{hrs}$. (S99) and (b) 10,000 hrs. (S67). Note elongated 'tail' in oxygen profile. 


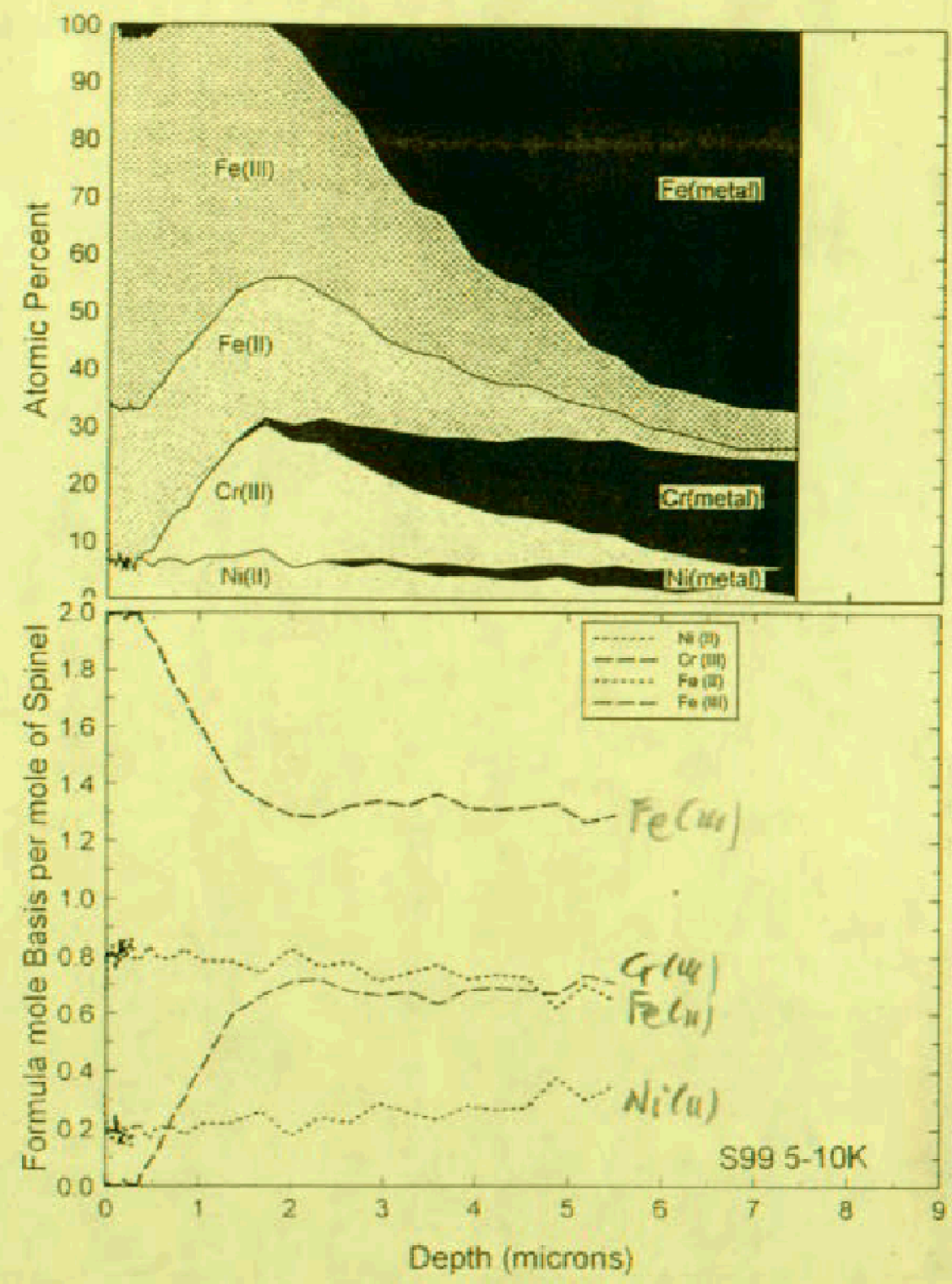

Fig. 6. Speciated composition profile of corroded 304 stainless steel surface after 5000 hrs. (S99). 


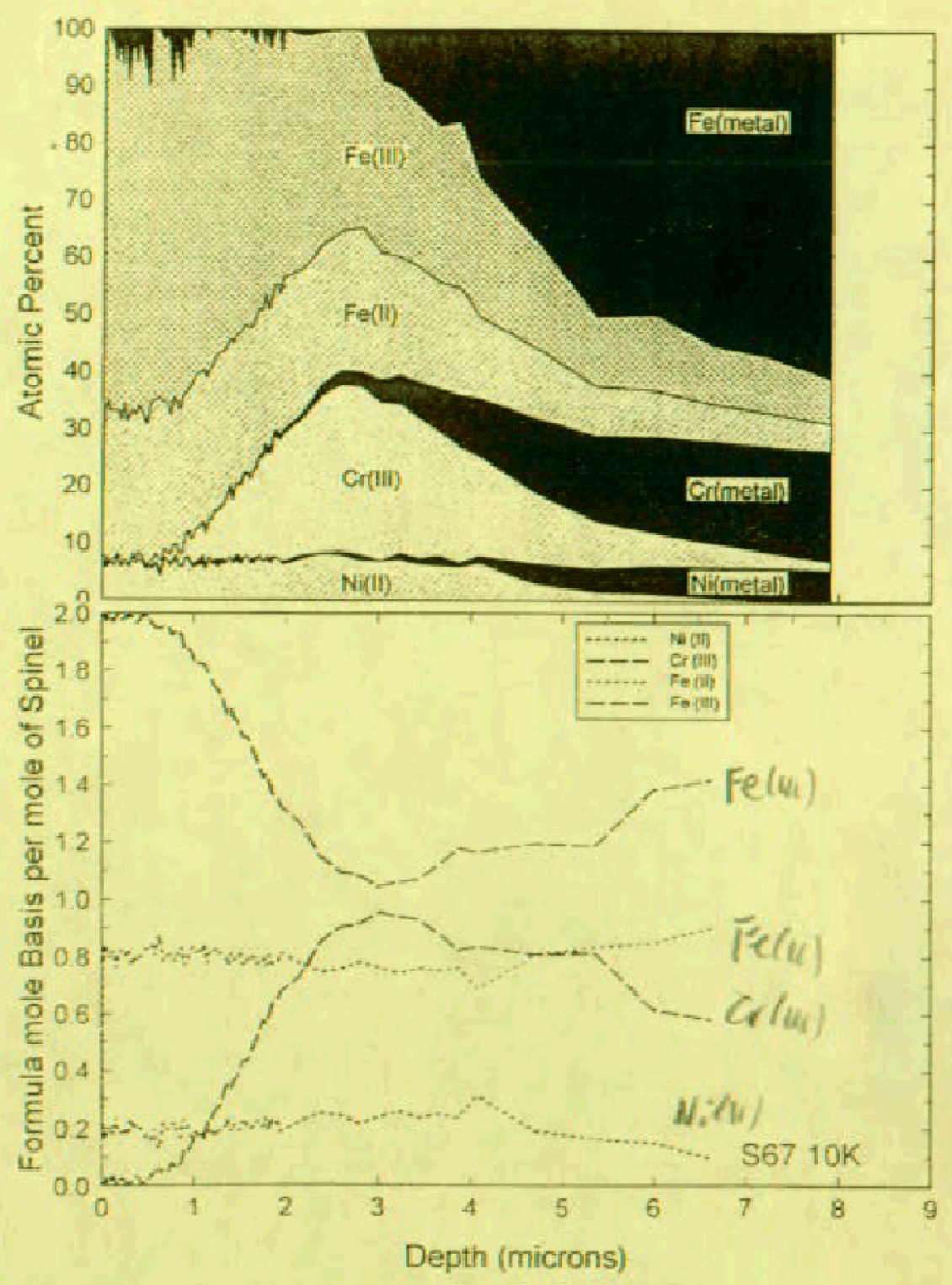

Fig. 7. Speciated composition profile of corroded 304 stainless steel surface after 10,000 hrs. (S67) 

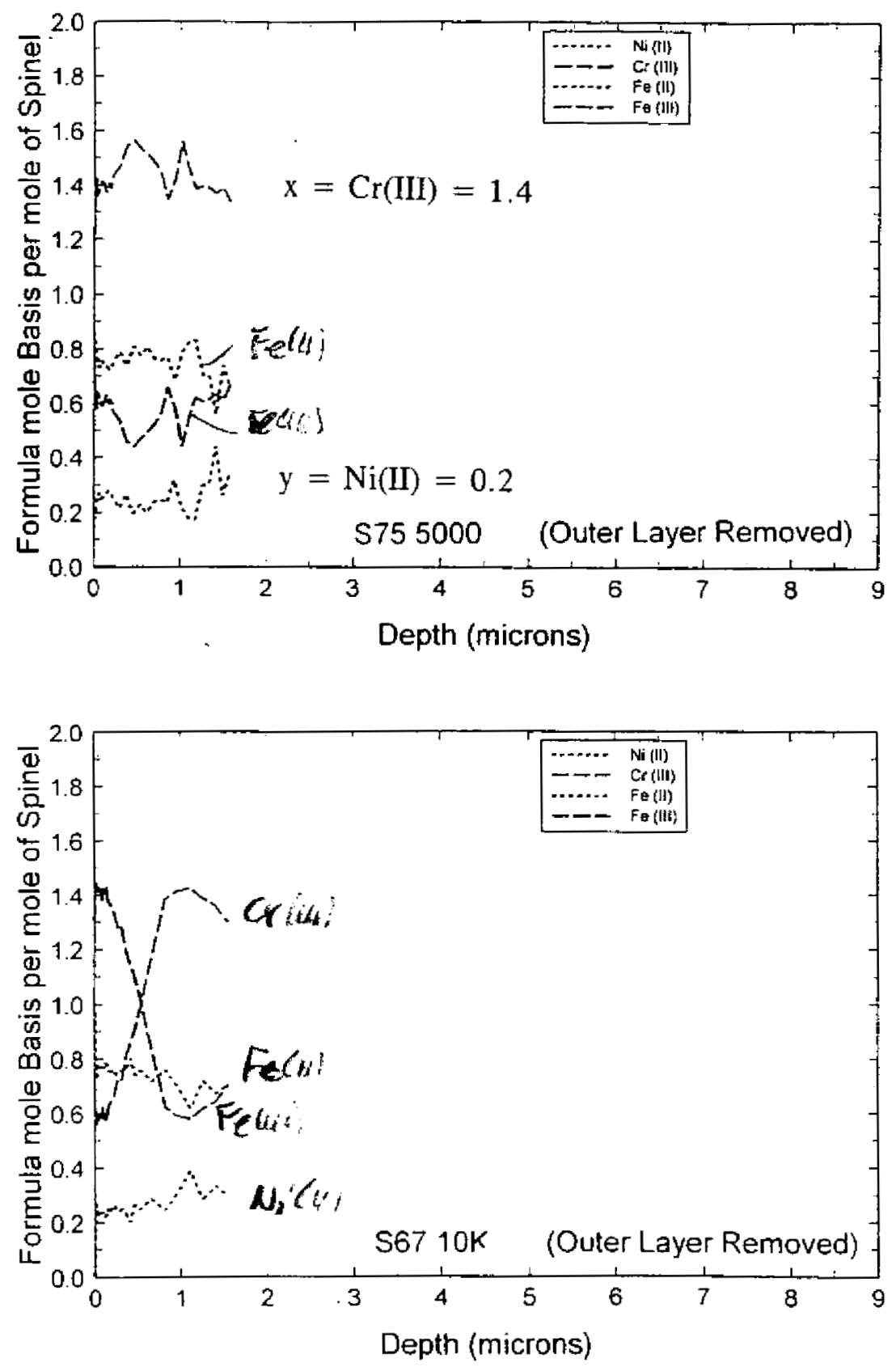

Fig. 8. Indicated stoichiometries of inner layer spinel $\left(\mathrm{Ni}_{y} \mathrm{Fe}_{1-\mathrm{y}}\right)\left(\mathrm{Fe}_{2-\mathrm{x}} \mathrm{Cr}_{\mathrm{x}}\right) \mathrm{O}_{4}$ on corroded specimens after mechanical removal of outer layer spinel crystals: (a) $5000 \mathrm{hr}$. (S75) and (b) 10,000 hr. (S67) 


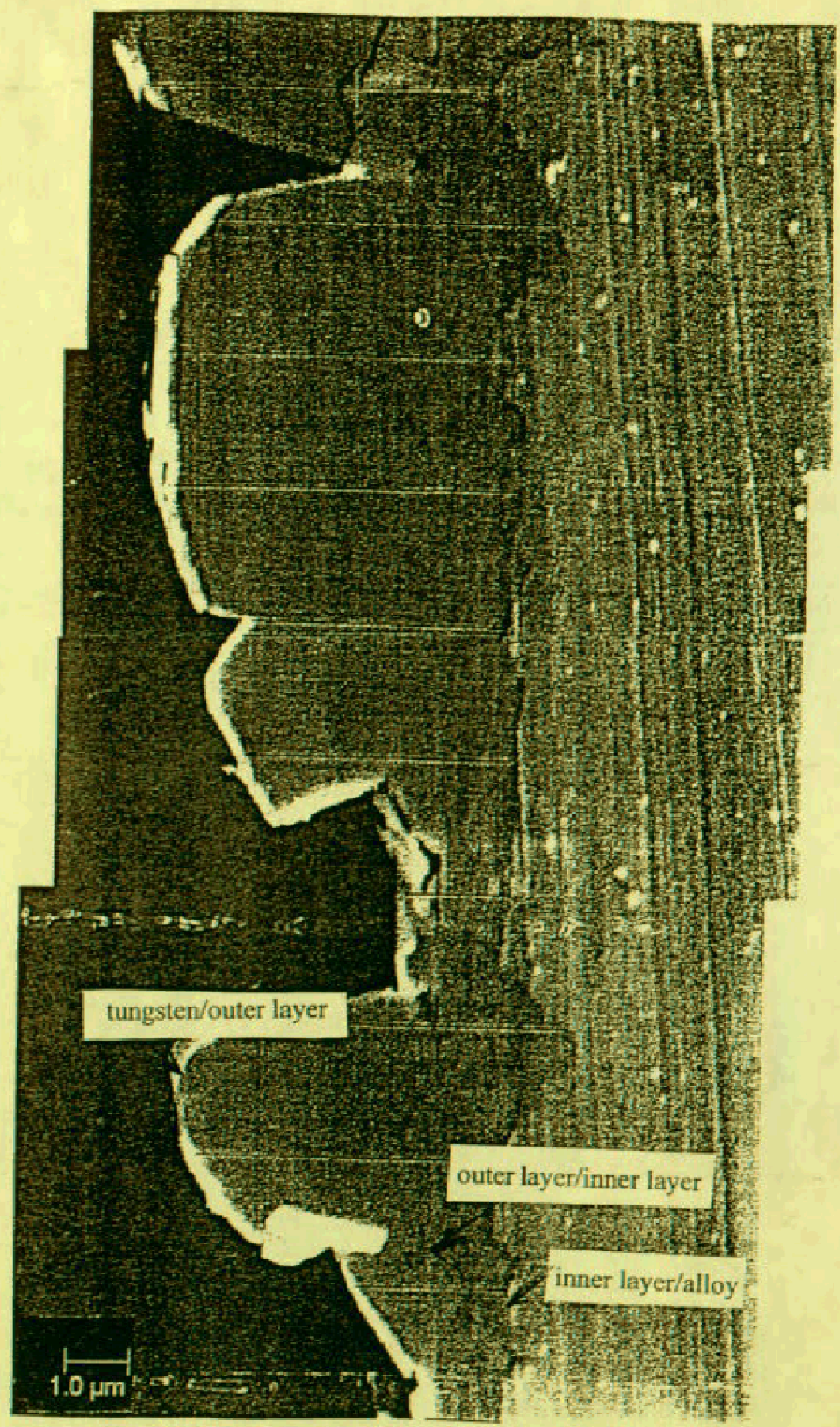

Fig. 9. Cross-sectional view of 304 stainless steel corrosion film. Note the straight-line demarcation between outer and inner layers, indicative of a smooth, highly-polished surface. 


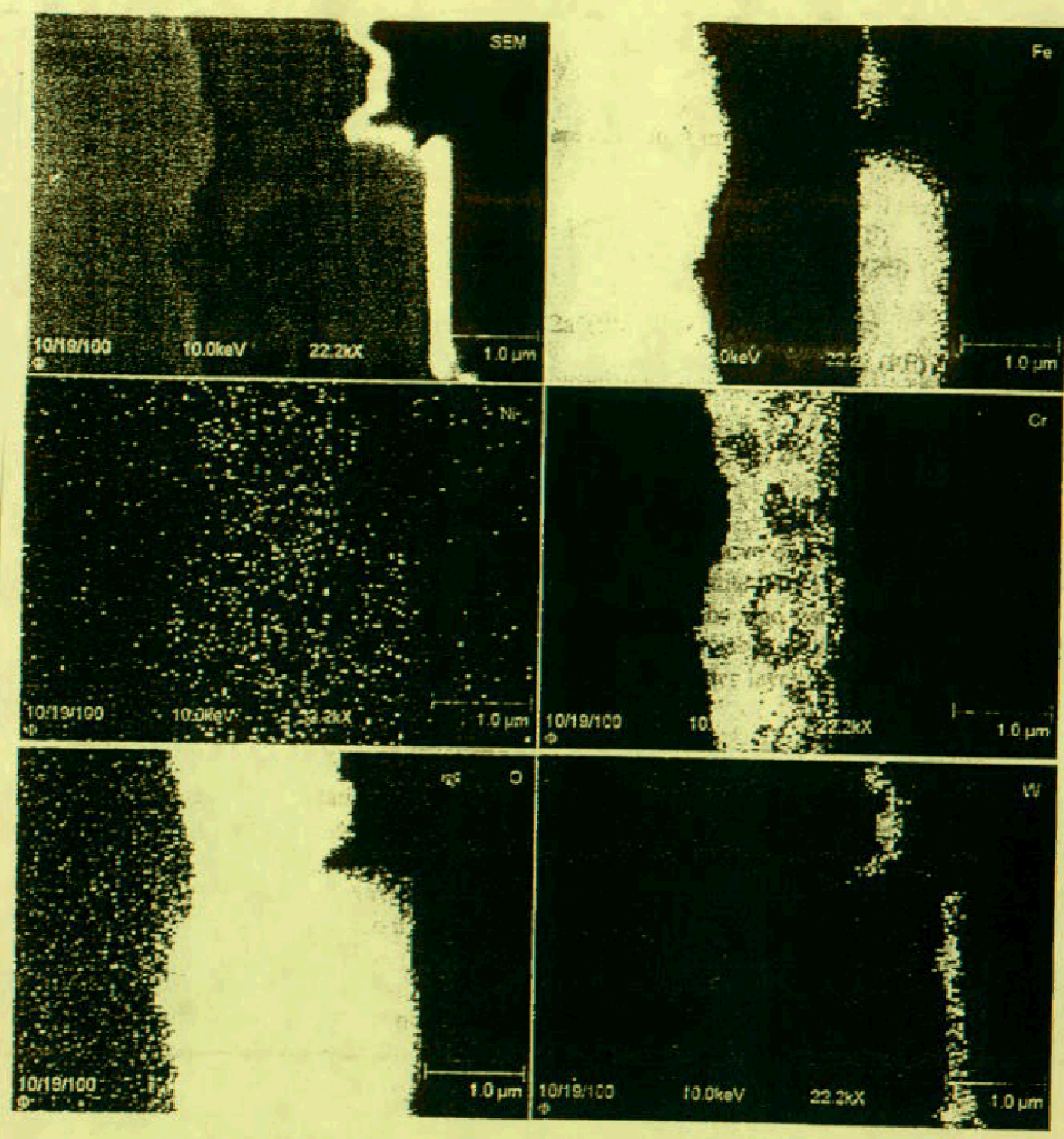

Low Concentration

High Concentration

Fig. 10. Elemental compositions of corrosion oxide cross-section shown in Fig. 9; (yellow > red). The Fe and $\mathrm{Cr}$ maps illustrate the remarkably straight-line boundary between the ferrite and chromite layers, corresponding to the initial surface. 